\section{Evaluation of sports character of university students who do sports in terms of various variables}

Spor yapan üniversite öğrencilerinin sportif karakter durumlarının çeşitli değişkenler açısından değerlendirilmesi

\author{
Yasin Y1d1z ${ }^{1}$ \\ Murat Özmaden ${ }^{2}$
}

\begin{abstract}
In this study, it is aimed to evaluate the sportive characteristics of university students who are actively involved in sports in terms of gender, age, education department, class and type of sport (team and individual). In addition to the personal information form for the demographic characteristics, the Sport Character Scale, developed by Chang-Yong Jang (2013) and adapted to Turkish by Görgüt and Tuncel (2017), was used. A total of 621 students 401 males (64.6\%), 220 females (35.4\%)) who were active in the individual and team and sports branches of the Sports Sciences Faculty of Aydin Adnan Menderes University were surveyed. The data obtained from the students were analyzed by using SPSS (Statistical Package for Social Sciences) v 25.0 package program, TTest, One-Way Analysis of Variance and Scheffe Test to determine that the groups were statistically different from each other.
\end{abstract}

According to the data obtained from the students who participated in the study, differences were found between the sporting character age, gender, class and type of sport. As a result of this research, it can be said that the

\section{Özet}

$\mathrm{Bu}$ araştırmada aktif olarak spor yapan üniversite ögrencilerinin sportif karakterlerinin cinsiyet, yaş, öğrenim görülen bölüm, sınıf ve yapılan spor türü (takım ve bireysel) açısından değerlendirilmesi amaçlanmıştır. Araştırmada demografik özellikler için kişisel bilgi formunun yaninda Chang-Yong Jang (2013) tarafindan geliştirilen ve Türkçe uyarlaması Görgüt ve Tuncel (2017) tarafindan yapılan Spor Karakter Ölçeği (Sport Character Scale), kullanılmıştır. Araştırmada Aydın Adnan Menderes Üniversitesi Spor Bilimleri Fakültesi'nde öğrenim gören bireysel ve takım ve spor branşlarında aktif olarak yer alan 401 erkek $(\% 64,6), 220$ kadın $(\% 35,4)$ olmak üzere toplamda 621 öğrenciye anket uygulanmıştır. Araştırmada öğrencilerden edilen veriler SPSS (Statistical Package For The Social Sciences) v 25.0 paket programı kullanilarak T-Testi, Tek Yönlü Varyans Analizi ve grupların birbirinden istatistiksel olarak farklı olduğunun belirlenmesinde Scheffe Testi kullanılmıştır.

Araştırmaya katılan öğrencilerde elde edilen veriler doğrultusunda sportif karakter yaş, cinsiyet öğrenim görülen sınıf ve yapılan spor

\footnotetext{
${ }^{1}$ Dr., Aydin Adnan Menderes University, Faculty of Sports Sciences, Department of Physical Education and Sports Education, yasinyildiz@hotmail.de Orcid ID: 0000-0003-3230-5717

2 Assist. Prof., Aydin Adnan Menderes University, Faculty of Sports Sciences, Department of Coaching Education, muratozmaden@yahoo.com :
} 
Yıldız, Y., \& Özmaden, M. (2019). Spor yapan üniversite öğrencilerinin sportif karakter durumlarının çeşitli değişkenler açısından değerlendirilmesi. Journal of Human Sciences, 16(4), 1197-1206. doi:10.14687/jhs.v16i4.5893

sporting characteristics of the students doing sports can be determined and evaluations can be made towards their goals.

Keywords: Sports, Character, University students.

(Extended English summary is at the end of this document) türü arasında istatiksel anlamda farklliklar tespit edilmiştir. $\mathrm{Bu}$ doğrultuda bu araştırma neticesinde spor yapan öğrencilerin sportif karakterlerinin saptanarak amaçları doğrultusunda hedeflerine yönelik değerlendirmeler yapılabileceği söylenebilir.

Anahtar Kelimeler: Spor, Karakter, Üniversite öğrencileri.

\section{Giriş}

Yaşanılan hayat içerisinde bireyler karşılaştıkları pek çok olumlu ya da olumsuz duruma farklı tepkiler gösterirler. Bunun altında kişinin sahip olduğu karakter yatmaktadır. Karakter, küçük yaşlardan itibaren içinde yaşanan toplumun değer yargılanının benimsenmesi ile şekillenir (Yıldız, 2019). Teo (2010), karakteri çok yüzlü, olaylar karşısında birinin iyi ahlaki hal göstermesine imkân tanıyan psikolojik ve davranışsal kaliteyi içeren, ahlaki sevgiye ve ahlaki davranışlara uygun erdemlere sahip olunması olarak tanımlamaktadır. Farklı bir bakış açısıyla değerlendirirsek, spor açısından karakteri göz önünde bulundurduğumuzda bu iki kavramın birbirinden çok uzak olmadığ1 düşünülebilir.

Spor karakteri şekillendirir ve mücadele etmeyi öğretir. Takım sporları iş birliği yapmayı, bireysel sporlar disiplini geliştirir (Tamminen ve ark., 2012). Tehlikeli sporlar cesareti arttırır. Bazı spor dalları yüksek iletişim değerlerine sahiptir. Özellikle bedensel temasın olduğu spor dallarında bu daha belirgindir. Spor saldırganlık dürtülerinin doğal yolla ve sosyal kurallara uyarak boşaltmayı öğretir (Gee, 2010).

Sporun ve karakter ilişkisini olumlu yönde desteklediği yönünde popüler görüşler de mevcuttur (Kavussanu ve Roberts, 2001; Sage, 1990; Sage ve Kavussanu, 2007). Takım arkadaşları ile iş birliği, müzakere ve ahlaki çatışmalara çözüm bulma, adalet, sportmenlik, ekip sadakati, ekip çalışması, sorumluluk ve daha büyük iyilik için boyun eğme gibi değerleri öğrenmede bir araç olarak kabul edilmektedir (Jang, 2013). Sporun içerisinde bulunan sporcu karakterinin yani adil, merhametli, dürüst ve sosyal olma gibi değerler ile bağdaşması ve spor alanlarında ortaya çıkacak sorunlarla mücadelede, profesyonelleşme sürecinin başlangıcının veya uzun sporculuk hayatının düzenli ve verimli ilerleyebilmesine yardımcı olacağı varsayımını güçlendirmektedir (Görgüt ve Tuncel, 2017).

$\mathrm{Bu}$ araştırmada aktif olarak spor yapan üniversite öğrencilerinin sportif karakterlerinin (alt boyutları ile birlikte centilmenlik, anti-sosyallik, dürüstlük, etik davranış) takım ve bireysel spor açısından yaş, cinsiyet, bölüm ve sınıf değişkenleri ile bu değişkenler aralanındaki farklılıkları incelemek amaçlanmıştır.

\section{Yöntem}

Bu araştırmada 2019-2020 akademik yll Aydın Adnan Menderes Üniversitesi Spor Bilimleri Fakültesi'nde öğrenim gören bireysel ve takım ve spor branşlarında aktif olarak yer alan 621 (n= 220 kadın, $n=401$ erkek) öğrenci yer almıştır. Araştırmanın amacı doğrultusunda demografik özellikler için kişisel bilgi formu hazırlanmış olup katıllımcılara Spor Karakter Ölçeği uygulanmıştır. Katılımcılara ait cinsiyet, yaş, öğrenim görülen bölüm, sınıf düzeyi, yapılan spor branş1 gibi demografik bilgilerini belirlemeye yönelik araştırmacı tarafından oluşturulan kişisel bilgi formu kullanilmıştır.

Chang-Yong Jang (2013) tarafindan geliştirilen Spor Karakter Ölçeği (Sport Character Scale) ve Türkçe uyarlaması Görgüt ve Tuncel (2017) tarafindan yapılmıştır. Spor Karakter Ölçeği, 5 faktör (1-10. maddeler dürüstlük; 11-15. maddeler anti-sosyal; 16-21. maddeler merhamet; 22-24. Maddeler sportmenlik ve 25-27. maddeler, adalet) ve 27 maddeden oluşmaktadır. Bu maddelerin 5'i olumsuz (madde 11, 12, 13, 14 ve 15) 22'si olumlu maddelerdir. Ölçeğin geçerlilik güvenirlik çalısması 
Yıldız, Y., \& Özmaden, M. (2019). Spor yapan üniversite öğrencilerinin sportif karakter durumlarının çeşitli değişkenler açısından değerlendirilmesi. Journal of Human Sciences, 16(4), 1197-1206. doi:10.14687/ihs.v16i4.5893

sonucunda madde toplam korelasyon değerlerinin. 33 ile. 67 arasında değişmesi, ölçek için sağlanan değerlerin yeterli olduğunu göstermektedir. Çalışmamızda ise ölçeğin güvenilirlik çalışmaları kapsamında Cronbach-alpha katsayısı .90 olarak hesaplanmıştır.

\section{Bulgular}

Araştırmaya katılan 621 kişiye ilişskin bulgular Tablo 1'de görülmektedir. Araştırmaya katılanların, \%35,4'ü kadın; \%64,6'sı erkek, \%47,3’ü 17 ile 20 yaş arasında; \%39,1’i beden eğitimi ve spor öğretmenliği bölümünde; \%40,1’i 1. sinıfta okumakta; \%59,3’ü takım sporlariyla ilgilenmektedir.

Tablo 1. Araştırmaya Katılan Kişilere Ait Özellikler ( $\mathrm{n}=621)$

\begin{tabular}{|l|c|c|}
\hline \multicolumn{1}{|c|}{ Gruplar } & Frekans & Yüzde \\
\hline Cinsiyet & 220 & 35,4 \\
\hline Kadın & 401 & 64,6 \\
\hline Erkek & 294 & 47,3 \\
\hline Yaş & 283 & 45,6 \\
\hline 17-20 Yaş Aras1 & 44 & 7,1 \\
\hline 21-24 Yaş Aras1 & \multicolumn{2}{|l|}{} \\
\hline 25 Yaş ve Üzeri & 243 & 39,1 \\
\hline Bölüm & 138 & 22,2 \\
\hline Beden Eğitimi ve Spor Öğretmenliği & 189 & 30,4 \\
\hline Antrenörlük Eğitimi & 51 & 8,2 \\
\hline Spor Yöneticiliği & 249 & 40,1 \\
\hline Rekreasyon & 92 & 14,8 \\
\hline Sinıf & 129 & 20,8 \\
\hline 1. sinıf & 151 & 24,3 \\
\hline 2. sinıf & \multicolumn{3}{|l|}{} \\
\hline 3. sinıf & 368 & 59,3 \\
\hline 4. sinıf & 253 & 40,7 \\
\hline Sportif Branş Türü &
\end{tabular}

Değişkenlerin cinsiyete göre farklllığı "Băğmsız Gruplar t Testi " ne göre analiz edilmiştir. Analiz sonuçları Tablo 2'de verilmektedir.

Tablo 2. Cinsiyete Göre Farklı1ık Analizi $(n=621)$

\begin{tabular}{|c|c|c|c|c|c|c|c|}
\hline & Cinsiyet & $\mathbf{N}$ & Ort. & Std. Sp. & f & $\mathrm{t}$ & $\mathrm{p}$ \\
\hline \multirow{2}{*}{ Centilmenlik } & Erkek & 401 & 4,0555 &, 71627 & \multirow[t]{2}{*}{6,343} & $-5,187$ & \multirow[b]{2}{*}{, $000^{*}$} \\
\hline & Kadin & 220 & 4,3446 &, 55683 & & $-5,575$ & \\
\hline \multirow{2}{*}{ Anti-Sosyal } & Erkek & 401 & 3,5466 & 1,04511 & \multirow[t]{2}{*}{1,816} & $-4,828$ & \multirow[b]{2}{*}{, $000^{*}$} \\
\hline & Kadin & 220 & 3,9645 & 1,00647 & & $-4,882$ & \\
\hline \multirow{2}{*}{ Dürüstlük } & Erkek & 401 & 4,1975 & ,78415 & \multirow[t]{2}{*}{8,585} & $-2,151$ & \multirow[b]{2}{*}{, $022^{*}$} \\
\hline & Kadin & 220 & 4,3291 & ,61612 & & $-2,305$ & \\
\hline \multirow{2}{*}{ Etik Davranış } & Erkek & 401 & 3,6434 & ,87211 & \multirow[t]{2}{*}{2,930} & $-3,437$ & \multirow[b]{2}{*}{, $000^{*}$} \\
\hline & Kadin & 220 & 3,8833 &, 75383 & & $-3,585$ & \\
\hline \multirow{2}{*}{ Spor Karakteri } & Erkek & 401 & 3,9276 & ,65401 & \multirow[t]{2}{*}{6,514} & $-5,392$ & \multirow[b]{2}{*}{, $000 *$} \\
\hline & Kadin & 220 & 4,2045 &, 52730 & & $-5,737$ & \\
\hline
\end{tabular}

Tablo 2'ye göre, centilmenlik, anti-sosyal, dürüstlük, etik davranış boyutları ve spor karakterine göre anlamlı düzeyde farklılık görülmektedir $(\mathrm{p}<0.05)$. Bulgular incelendiğinde; kadınların centilmenlik $\left(\mathrm{X}_{\mathrm{K}}=4,34 \mathrm{X}_{\mathrm{E}}=4,05\right.$,), anti-sosyal $\left(\mathrm{X}_{\mathrm{K}}=3,96 \mathrm{X}_{\mathrm{E}}=3,54\right.$, ), dürüstlük $\left(\mathrm{X}_{\mathrm{K}}=4,32 \mathrm{X}_{\mathrm{E}}=4,19\right.$,), 
Yıldız, Y., \& Özmaden, M. (2019). Spor yapan üniversite öğrencilerinin sportif karakter durumlarının çeşitli değişkenler açısından değerlendirilmesi. Journal of Human Sciences, 16(4), 1197-1206. doi:10.14687/ihs.v16i4.5893

etik davranış $\left(X_{K}=3,88 X_{E}=3,64,\right)$, spor karakteri $\left(X_{K}=4,20 \quad X_{E}=3,92\right.$,), ortalaması erkeklere göre daha yüksek olduğu görülmektedir.

Tablo 3. Değişkenlerin Yaşa Göre Betimsel Bulguları $(n=621)$

\begin{tabular}{|c|c|c|c|c|}
\hline & & $\mathbf{N}$ & Ort. & Std. Sp. \\
\hline \multirow{4}{*}{ Centilmenlik } & $17-20$ & 294 & 4,2134 & 67025 \\
\hline & $21-24$ & 283 & 4,1089 & ,67756 \\
\hline & 25 ve + & 44 & 4,1033 & ,71839 \\
\hline & Toplam & 621 & 4,1580 & 67799 \\
\hline \multirow{4}{*}{ Anti-Sosyal } & $17-20$ & 294 & 3,8048 & 1,03422 \\
\hline & $21-24$ & 283 & 3,5823 & 1,05728 \\
\hline & 25 ve + & 44 & 3,6818 & 1,05418 \\
\hline & Toplam & 621 & 3,6947 & 1,05000 \\
\hline \multirow{4}{*}{ Dürüstlük } & $17-20$ & 294 & 4,3184 & ,72187 \\
\hline & $21-24$ & 283 & 4,1880 & ,71657 \\
\hline & 25 ve + & 44 & 4,1091 & 84573 \\
\hline & Toplam & 621 & 4,2441 & ,73127 \\
\hline \multirow{4}{*}{ Etik Davranış } & $17-20$ & 294 & 3,7098 & ,88021 \\
\hline & $21-24$ & 283 & 3,7456 & 80020 \\
\hline & 25 ve + & 44 & 3,7424 & ,82237 \\
\hline & Toplam & 621 & 3,7284 & ,83941 \\
\hline \multirow{4}{*}{ Spor Karakteri } & $17-20$ & 294 & 4,0872 &, 62660 \\
\hline & $21-24$ & 283 & 3,9703 & ,61181 \\
\hline & 25 ve + & 44 & 3,9716 &, 68505 \\
\hline & Toplam & 621 & 4,0257 &, 62590 \\
\hline
\end{tabular}

Tablo 3 incelendiğinde, değişkenlerin yaş gruplarının ortalamasına göre farkllık gösterdiği görülmektedir. Bu farklılığın istatistiki olarak anlamlıllğının tespiti için "Tek Yönlü ANOVA Analizį" sonuçları Tablo 4'de verilmektedir.

Tablo 4. Yaşa Göre Farklılık Analizi (n=621)

\begin{tabular}{|c|c|c|c|c|c|c|}
\hline & & Kareler Top. & sd & Kareler Ort. & $\mathbf{F}$ & $\mathrm{p}$ \\
\hline \multirow{3}{*}{ Centilmenlik } & Gruplar Arası & 1,715 & 2 &, 857 & 1,871 & , 155 \\
\hline & Grup İçi & 283,279 & 618 & , 458 & & \\
\hline & Toplam & 284,994 & 620 & & & \\
\hline \multirow{3}{*}{ Anti-Sosyal } & Gruplar Aras1 & 7,142 & 2 & 3,571 & 3,263 & ,039* \\
\hline & Grup İçi & 676,410 & 618 & 1,095 & & \\
\hline & Toplam & 683,552 & 620 & & & \\
\hline \multirow{3}{*}{ Dürüstlük } & Gruplar Arası & 3,315 & 2 & 1,657 & 3,120 &, $045^{*}$ \\
\hline & Grup İçi & 328,236 & 618 & ,531 & & \\
\hline & Toplam & 331,551 & 620 & & & \\
\hline \multirow{3}{*}{ Etik Davranış } & Gruplar Aras1 & ,194 & 2 & ,097 & ,138 & 871 \\
\hline & Grup İçi & 436,662 & 618 &, 707 & & \\
\hline & Toplam & 436,856 & 620 & & & \\
\hline \multirow{3}{*}{$\begin{array}{c}\text { Spor } \\
\text { Karakteri }\end{array}$} & Gruplar Arası & 2,109 & 2 & 1,055 & 2,707 & 068 \\
\hline & Grup İçi & 240,774 & 618 & ,390 & & \\
\hline & Toplam & 242,883 & 620 & & & \\
\hline
\end{tabular}

Tablo 4'e göre, centilmenlik, etik davranış ve spor karakteri yaşa göre farkllilk göstermemektedir $(\mathrm{p}>0,05)$. Ancak, anti-sosyal ve dürüstlük alt boyutları ile yaş arasında istatistiki olarak anlamlı bir farklılık bulunmaktadır $(\mathrm{p}<0.05)$. Grupların birbirinden istatistiki olarak farklı 
Yıldız, Y., \& Özmaden, M. (2019). Spor yapan üniversite öğrencilerinin sportif karakter durumlarının çeşitli değişkenler açısından değerlendirilmesi. Journal of Human Sciences, 16(4), 1197-1206. doi:10.14687/ihs.v16i4.5893

olduğunu belirlemek için ikili karşılaştırma testlerinden "Scheffe Testi” yapılmıştır. Tablo 5, Scheffe Testi sonuçlarını vermektedir.

Tablo 5. Yaşa Göre Scheffe Testi Sonuçları

\begin{tabular}{|l|c|c|c|c|c|}
\hline \multicolumn{1}{|c|}{ Değişken } & $\begin{array}{c}\text { Yaş } \\
\text { (I) }\end{array}$ & $\begin{array}{c}\text { Yaş } \\
\text { (J) }\end{array}$ & $\begin{array}{c}\text { Ortalama } \\
\text { Fark1 (I-J) }\end{array}$ & $\begin{array}{c}\text { Standart } \\
\text { Hata }\end{array}$ & $\begin{array}{c}\text { Anlamlılık } \\
\text { Düzeyi }\end{array}$ \\
\hline Anti-sosyal & $17-20$ & $21-24$ &, $22243^{*}$ &, 08712 &, 039 \\
\hline
\end{tabular}

Tablo 5'deki analiz sonuçları incelendiğinde, 17 ile 20 yaşında olan bireylerin anti-sosyal davranışları 21 ile 24 yaş arasındaki bireylerden daha yüksektir.

Tablo 6. Bölümlere Göre Farklılık Analizi (n=621)

\begin{tabular}{|c|c|c|c|c|c|c|}
\hline & & $\begin{array}{c}\text { Kareler } \\
\text { Top. }\end{array}$ & sd & Kareler Ort. & F & $\mathrm{p}$ \\
\hline \multirow{3}{*}{ Centilmenlik } & Gruplar Arası &, 701 & 3 & ,234 &, 507 & ,677 \\
\hline & Grup İçi & 284,292 & 617 & ,461 & & \\
\hline & Toplam & 284,994 & 620 & & & \\
\hline \multirow{3}{*}{ Anti-Sosyal } & Gruplar Arası & 5,790 & 3 & 1,930 & 1,757 & ,154 \\
\hline & Grup İçi & 677,763 & 617 & 1,098 & & \\
\hline & Toplam & 683,552 & 620 & & & \\
\hline \multirow{3}{*}{ Dürüstlük } & Gruplar Arası & 2,380 & 3 & ,793 & 1,487 & ,217 \\
\hline & Grup İçi & 329,171 & 617 & ,534 & & \\
\hline & Toplam & 331,551 & 620 & & & \\
\hline \multirow{3}{*}{ Etik Davranış } & Gruplar Arası & 3,075 & 3 & 1,025 & 1,458 & ,225 \\
\hline & Grup İçi & 433,781 & 617 &, 703 & & \\
\hline & Toplam & 436,856 & 620 & & & \\
\hline \multirow{3}{*}{ Spor Karakteri } & Gruplar Arası & 1,589 & 3 & ,530 & 1,354 & ,256 \\
\hline & Grup İçi & 241,294 & 617 & ,391 & & \\
\hline & Toplam & 242,883 & 620 & & & \\
\hline
\end{tabular}

Tablo 6’ya göre, centilmenlik, anti-sosyal, dürüstlük, etik davranış ve spor karakteri bölüme göre farklılık göstermemektedir ( $\mathrm{p}>0,05)$.

Tablo 7. Öğrenim Görülen Sınıf Düzeylerine Göre Farklılık Analizi (n=621)

\begin{tabular}{|c|c|c|c|c|c|c|}
\hline & & Kareler Top. & sd & Kareler Ort. & $\mathbf{F}$ & $\mathrm{p}$ \\
\hline \multirow{3}{*}{ Centilmenlik } & Gruplar Aras1 & 6,067 & 3 & 2,022 & 4,474 &, $004 *$ \\
\hline & Grup İçi & 278,926 & 617 & ,452 & & \\
\hline & Toplam & 521,711 & 1203 & & & \\
\hline \multirow{3}{*}{ Anti-Sosyal } & Gruplar Aras1 & 16,641 & 3 & 5,547 & 5,132 &, $002 *$ \\
\hline & Grup İçi & 666,911 & 617 & 1,081 & & \\
\hline & Toplam & 683,552 & 620 & & & \\
\hline \multirow{3}{*}{ Dürüstlük } & Gruplar Aras1 & 8,102 & 3 & 2,701 & 5,152 &, $002 *$ \\
\hline & Grup İçi & 323,449 & 617 &, 524 & & \\
\hline & Toplam & 331,551 & 620 & & & \\
\hline \multirow{3}{*}{ Etik Davranış } & Gruplar Aras1 & 2,852 & 3 & ,951 & 1,352 & ,257 \\
\hline & Grup İçi & 434,004 & 617 & ,703 & & \\
\hline & Toplam & 436,856 & 620 & & & \\
\hline \multirow{3}{*}{ Spor Karakteri } & Gruplar Aras1 & 7,159 & 3 & 2,386 & 6,246 &, $000 *$ \\
\hline & Grup İçi & 235,724 & 617 & ,382 & & \\
\hline & Toplam & 242,883 & 620 & & & \\
\hline
\end{tabular}

Tablo 7'ye göre, etik davranış alt boyutu öğrenim görülen sınıf düzeyine göre farklilık göstermemektedir $(\mathrm{p}>0,05)$. Centilmenlik, anti-sosyal, dürüstlük ve spor karakteri ile öğrenim görülen sınıf düzeyleri arasında istatistiki olarak anlamlı bir farklılık bulunmaktadır $(\mathrm{p}<0.05)$. 
Yıldız, Y., \& Özmaden, M. (2019). Spor yapan üniversite öğrencilerinin sportif karakter durumlarının çeşitli değişkenler açısından değerlendirilmesi. Journal of Human Sciences, 16(4), 1197-1206. doi:10.14687/ihs.v16i4.5893

Grupların birbirinden istatistiki olarak farklı olduğunu belirlemek için ikili karşılaştırma testlerinden "Scheffe Testi” yapılmıştur. Tablo 8, Scheffe Testi sonuçlanını vermektedir.

Tablo 8. Öğrenim Görülen Sınıfa Göre Scheffe Testi Sonuçları

\begin{tabular}{|c|c|c|c|c|c|}
\hline Değişken & $\begin{array}{c}\text { Sinıf } \\
(\mathbf{I})\end{array}$ & $\begin{array}{c}\text { Sinıf } \\
(\mathbf{J})\end{array}$ & $\begin{array}{c}\text { Ortalama } \\
\text { Fark1 (I-J) }\end{array}$ & $\begin{array}{c}\text { Standart } \\
\text { Hata }\end{array}$ & $\begin{array}{c}\text { Anlamlilı } \\
\text { k Düzeyi }\end{array}$ \\
\hline Centilmenlik & 1. sinıf & 2. sinıf &, $26087^{*}$ &, 08203 &, 018 \\
\hline \multirow{2}{*}{ Anti-Sosyal } & \multirow{2}{*}{ 1. sinıf } & 2. sinıf &, $37933^{*}$ &, 12685 &, 031 \\
\cline { 3 - 6 } & & 3. sinıf &, $33423^{*}$ &, 11278 &, 033 \\
\hline \multirow{2}{*}{ Dürüstlük } & 1. sinıf & 2. sinif &, $30530^{*}$ &, 08834 &, 008 \\
\cline { 2 - 6 } & 4. sinıf & 1. sinif &,$- 21110^{*}$ &, 07468 &, 047 \\
\hline \multirow{2}{*}{ Spor Karakteri } & 1. sinıf & 2. sinif &, $28013^{*}$ &, 07541 &, 003 \\
\cline { 2 - 6 } & 4. sinıf & 1. sinif &,$- 19696^{*}$ &, 06375 &, 024 \\
\hline
\end{tabular}

Tablo 8'deki analiz sonuçlarına bakıldığında, centilmenlik değisskeni, 1. sınıfta okuyan öğrencilerin 2. sınıfta okuyan öğrencilere göre ortalaması daha yüksektir. Ayrıca 1. sinıf öğrencilerin anti-sosyal değişken ortalaması 2. sınıf ve 3. sınıf öğrencilerden daha yüksektir. 1. sınıf öğrencilerin dürüstlük değişken ortalaması 2. sınıf öğrencilerden daha yüksektir. Aynı zamanda 4. sınıf öğrencilerin dürüstlük değissken ortalaması 1. sınıf öğrencilerden daha yüksektir. 1. sinıf öğrencilerin spor karakteri değişken ortalaması 2. sınıf öğrencilerden daha yüksektir. Aynı zamanda 4. sınıf öğrencilerin de spor karakteri değişken ortalaması 1. sınıf öğrencilerden daha yüksektir.

Tablo 9. Yapılan Takım ve Bireysel Spor Durumuna Göre Farklılık Analizi

\begin{tabular}{|c|c|c|c|c|c|c|c|}
\hline Değişken & Spor Türü & $\mathbf{N}$ & Ort. & Std. Sp. & f & t & $\mathrm{p}$ \\
\hline \multirow{2}{*}{ Centilmenlik } & Takım & 368 & 4,0929 &, 72913 & \multirow{2}{*}{4,936} & \multirow{2}{*}{$-2,902$} & \multirow{2}{*}{, $004^{*}$} \\
\hline & Bireysel & 253 & 4,2526 &, 58440 & & & \\
\hline \multirow{2}{*}{ Anti-Sosyal } & Takım & 368 & 3,5728 & 1,05754 & \multirow{2}{*}{1,013} & \multirow{2}{*}{$-3,520$} & \multirow{2}{*}{, $000^{*}$} \\
\hline & Bireysel & 253 & 3,8719 & 1,01514 & & & \\
\hline \multirow{2}{*}{ Dürüstlük } & Takım & 368 & 4,1875 &, 77125 & \multirow{2}{*}{1,176} & \multirow{2}{*}{$-2,335$} & \multirow{2}{*}{, $020^{*}$} \\
\hline & Bireysel & 253 & 4,3265 & 66175 & & & \\
\hline \multirow{2}{*}{$\begin{array}{l}\text { Etik } \\
\text { Davranış }\end{array}$} & Takım & 368 & 3,5797 & 85648 & \multirow{2}{*}{2,154} & \multirow[b]{2}{*}{$-5,445$} & \multirow{2}{*}{, $000^{*}$} \\
\hline & Bireysel & 253 & 3,9447 &, 76550 & & & \\
\hline \multirow{2}{*}{$\begin{array}{l}\text { Spor } \\
\text { Karakteri }\end{array}$} & Takım & 368 & 3,9401 & 66601 & \multirow{2}{*}{4,353} & \multirow{2}{*}{$-4,164$} & \multirow{2}{*}{, $000^{*}$} \\
\hline & Bireysel & 253 & 4,1502 & ,53998 & & & \\
\hline
\end{tabular}

Tablo 9'a göre, centilmenlik, anti-sosyal, dürüstlük, etik davranış ve spor karakteri alt boyutları spor türüne göre aralarında istatistiki olarak anlamlı bir farklılık bulunmaktadır $(\mathrm{p}<0.05)$. Centilmenlik, anti-sosyal, dürüstlük, etik davranışve spor karakterideğişkenleri spor türüne göre incelendiğinde, bireysel spor ile uğraşan kişilerin centilmenlik $\left(X_{B}=4,25, X_{T}=4,09\right)$, anti-sosyal $\left(X_{B}=3,87, X_{T}=3,57\right)$, dürüstlük $\left(X_{B}=4,32, X_{T}=4,18\right)$, etik davranış $\left(X_{B}=3,94, X_{T}=3,57\right)$ ve spor karakteri $\left(\mathrm{X}_{\mathrm{B}}=4,15, \mathrm{X}_{\mathrm{T}}=3,94\right)$ değişkenler ortalamaları takım sporu ile uğraşan öğrencilere göre daha yüksek olduğu tespit edilmiştir.

\section{Tartışma ve Sonuç}


Yıldız, Y., \& Özmaden, M. (2019). Spor yapan üniversite öğrencilerinin sportif karakter durumlarının çeşitli değişkenler açısından değerlendirilmesi. Journal of Human Sciences, 16(4), 1197-1206. doi:10.14687/jhs.v16i4.5893

Günümüzde sportif faaliyetlere katılan bireylerin yaptıkları branş doğrultusunda bazı karakteristik değişimlere uğradığ1 görülmektedir. Bireyler, fiziksel görünümleri ile olduğu kadar tutum ve davranışları itibariyle de birbirlerinden farklilıklar gösterirler, olaylar insanların hareketleri, duygulan ve fikirleri bakımından birbirlerinden farklı olduklarını göstermektedir (Eren, 2001). Sporun, karakter oluşumu ve kişilik niteliklerinin gelişiminde rol oynadığı birçok eğitimci tarafından kabul edilmektedir. Spor dünyas1, sürekli olarak "en yüksek performans " kavramı üzerine kurulu olduğu için, sporcu kişiliğinin, ruhsal ve fiziksel bütün güçlerini kullanarak en yüksek performansa ulaşmaya hazır ve buna ulaşmak için gerekli fedakârlı̆̆1 yapmaya uygun bir kişilik olması gerekir (Akin, 2015).

Kadınların centilmenlik davranışları, anti-sosyal tutumları, dürüstlük ve etik davranış değerleri aynı zamanda spor karakteri toplamında, değişken ortalamalarının erkeklere göre daha yüksek olduğu tespit edilmiştir (Tablo 2). Buradan yola çıkarak kadınların sportif hedeflere ulaşmasında motivasyonlarının daha yüksek olduğu, kadınlardaki centilmenlik, anti-sosyal, dürüstlük, etik davranış ve spor karakteri değişkenlerinin erkeklere göre daha yüksek olması kadınların bulundukları toplumsal ve dış etkenlerden kaynaklandığ1 söylenebilir.

İmamlı ve Ünver (2018)'in yapmış oldukları çalışmada kadın sporcuların anti-sosyallik alt boyutunun erkek sporculara göre daha yüksek olduğu sonucuna ulaşıllırken, buna karşın Siyahtaş ve arkadaşlarının (2018) yapmış olduğu çalışmada erkek sporcuların kadın sporculardan daha antisosyal olduğu tespit edilmiştir. Anti-sosyallik durumunun sporcular arasında cinsiyetlere göre farklılık göstermesinin pek çok sebebi olabilir. Bu sebeplerin başında kadının içinde yaşadığı sosyal çevre, toplumsal cinsiyet ayrımı ve ona dayalı haksız tanımlama, konumlandırma ve uygulamalar gelmektedir (Bingöl, 2014). Dolayısıyla toplumun ve çevresel etkenlerin kadın sporcuların üzerinde önemli bir etkisinin olduğu söylenebilir.

Tablo 4'e bakıldığında, centilmenlik, etik davranış ve spor karakteri yaşa göre farklılık göstermemektedir ( $\mathrm{p}>0,05)$. Ancak, 17 ile 20 yaşında olan bireylerin anti-sosyal davranışları 21 ile 24 yaş arasındaki bireylerden daha yüksek olduğu saptanmıştır (Tablo 5). Öğrencilerin 17-20 yaş grubunun genel kişisel yapıları, özellikleri ve yeteneklerine ilişkin etkenler ve yaşanmışlkların azlı̆̆ anti-sosyal davranışların yüksek olmasına neden olduğu söylenebilir.

Tablo 6'ya göre, centilmenlik, anti-sosyal, dürüstlük, etik davranış ve spor karakteri bölüme göre farklılık göstermediği tespit edilmiştir ( $\mathrm{p}>0,05)$. Tablo 7'ye göre, sadece etik davranış alt boyutunda öğrenim görülen sınıf düzeyi açısından farklılık tespit edilmemiştir $(p>0,05)$. Centilmenlik, anti-sosyal, dürüstlük ve spor karakteri ile öğrenim görülen sınıf düzeyleri arasında istatistiki olarak anlamlı bir farklılık bulunmuştur $(\mathrm{p}<0.05)$.

Tablo 8'de, 1. Sınıfta okuyan öğrencilerin centilmenlik değişkeni ortalama farkı 2. sınıfta öğrenim gören öğrencilerinkinden yüksek olduğu ve 1 . sınıf öğrencilerin anti-sosyal değişken ortalama farkının 2. ve 3. sınıf öğrencilerinkinden daha yüksek olduğu sonucuna ulaşılmıştır. 1. sınıf öğrencilerin dürüstlük değişken ortalama farkı 2. sınıf öğrencilerden daha yüksek olduğu ve 4. sınıf öğrencilerin dürüstlük değissken ortalama farkının da 1. sınıf öğrencilerden daha yüksek olduğu tespit edilmiştir.

1. sınıf öğrencilerin spor karakteri değişken ortalaması 2. sınıf öğrencilerden daha yüksek olduğu ve 4. sınıf öğrencilerin de spor karakteri değişken ortalaması 1. sinıf öğrencilerden daha yüksek olduğu sonuçlarına ulaşılmıştır.

Tablo 9’a göre, centilmenlik, anti-sosyal, dürüstlük, etik davranış ve spor karakteri alt boyutları spor türüne göre aralarında istatistiki olarak anlamlı bir farklılık olduğu bulunmuştur $(\mathrm{p}<0.05)$.

Centilmenlik, anti-sosyal, dürüstlük, etik davranış ve spor karakteri değişkenleri spor türüne göre incelendiğinde, bireysel spor ile uğraşan kişilerin centilmenlik, anti-sosyal, dürüstlük, etik davranış ve spor karakteri değişkenler ortalamaları takım sporu ile uğraşan öğrencilere göre daha yüksek olduğu sonucuna ulaşılmıstır. Bu bağlamda bireysel sporcular takım sporcularına göre herhangi bir müsabaka ya da maç esnasında kendi motivasyonlarını kendileri sağlamakla sorumlu olduklarından sportif karakterlerinin takım sporcularına göre farklı olmasının sebebi bilişsel yapılanma aracılı̆̆ıyla kendilerine olan özgüvenlerini daha iyi yönetebileceklerinden takım 
Yıldız, Y., \& Özmaden, M. (2019). Spor yapan üniversite öğrencilerinin sportif karakter durumlarının çeşitli değişkenler açısından değerlendirilmesi. Journal of Human Sciences, 16(4), 1197-1206. doi:10.14687/jhs.v16i4.5893

arkadaşlarının etkisinde kalmadan bu tür davranışlanı kendisi daha iyi kontrol edebilmesinden kaynaklandığı düşünülebilir.

*Bu araştırma sonunda diğer fakültelerde spor yapan öğrenciler de çalışmaya dâhil edilip sporun içerinde çeşitli faktörlerin etkisi de incelenebilir.

*Spor karakteri davranışlarını geliştirici ek çalışmalar ve etkinlikler ile sportif başarıyı arttırmak için uygulamalar düzenlenebilir.

*Bireyin iyi karakter sürecinin bir parçası öğrencilere olacak karakter gelişimi eğitimleri sağlanabilir.

*Başka bir araştırmada spor karakteri davranışları spor branşları açısından değerlendirilebilir.

* Öğrencilerin bireysel özellikleri daha iyi tanınmalı, kişilik ve karakteristik özellikleri dikkate alınmalı ve bu değerlerin geliştirilmesi için çalışmalar yapılmalıdır.

\section{Kaynakça}

Akın, T. (2015). Futbol Oyuncularının Ego Durumlarıyla Takımlardaki Pozisyonlarının Uyuşma Bağdaşıklık Düzeyinin Saha İçi Performansları İle İlişkisi (Master's Thesis, İstanbul Arel Üniversitesi Sosyal Bilimler Enstitüsü).

Bingöl, O. (2014). Toplumsal Cinsiyet Olgusu ve Türkiye'de Kadınlık. KMÜ Sosyal ve Ekonomik Araştırmalar Dergisi 16 (Özel Sayı I): 108-114.

Eren, E. (2001). Örgütsel Davranış ve Yönetim Psikolojisi (7. Baskı). İstanbul: Beta.

Eren, Y. K. (2001). Eğitim-Öğretimde Çoklu Zekâ Teorisi ve Uygulamaları, Özel Cüceli Okulları Yayınları, Ankara.

Gee, C. J. (2010). How Does Sport Psychology Actually İmprove Athletic Performance? A Framework to Facilitate Athletes' and Coaches' Understanding, Behavior Modification, 34, 386-402.

Görgüt İ. ve Tuncel S. (2017). Spor Karakter Ölçeğinin Türkçeye Uyarlanması, SPORMETRE, 15 (3), 149156.

İmaml, H. ve Ünver, G. (2018). Spor Karakterinin Demografik Nitelikler Açısından İncelenmesi. Akdeniz Spor Bilimleri Dergisi, 1(1), 36-49.

Jang C.Y. (2013). Development and Validation Of The Sport Character Scale. Doctora tethesis, The University of Utah, USA.

Kavussanu, M. ve Roberts, G. C. (2001). Moral Functioning İn Sport: An Achievement Goal Perspective, Journal of Sport and Exercise Psychology, 23 (1), 37-54.

Sage, L. ve Kavussanu, M. (2007). The Effects of Goal Involvement on Moral Behavior in An Experimentally Manipulated Competitive Setting, Journal of Sport and Exercise Psychology, 29 (2), 190-207.

Siyahtaş, A., Saraç, D., Tükenmez, A., Hocaoğlu, M. (2018). "Farklı Branşlardaki Sporcuların Spor Karakter Özelliklerinin Karşılaştırılması”, International Social Sciences Studies Journal, 4 (28): 6252-6259.

Tamminen K. A., Holt N. L., Crocker P. R. E. (2012). Adolescent Athletes: Psychosocial Challenges and Clinical Concerns, Child and Adolescent Psychiatry, 25, 293-300.

Teo, W. (2010). The Effectiveness in Measuring Character Development Outcomes in Singapore Schools Through The Character Development Award (Doctoral thesis, University of Durham).

Yıldız, Y. (2019). "Bireysel Ve Takım Sporcularının Sportif Karakterlerinin ve Zekâ Boyutlarının Sportif Başarı Motivasyonları Üzerine Etkisinin İncelenmesi”, Doktora Tezi, Muğla Sttkı Koçman Üniversitesi, Sağlık Bilimleri Enstitüsü, Beden Eğitimi ve Spor Anabilim Dalı, Muğla.

\section{Extended English Summary}

\section{Introduction}

Sport shapes personality and teaches to struggle. Team sports improves collaboration, while individual sports improve discipline. Extreme sports, on the other hand, boost courage. Some sport branches have high values of communication. This is more remarkable in especially sport branches where body contact exists. Sport teaches to release aggressive impulses through natural 
Yıldız, Y., \& Özmaden, M. (2019). Spor yapan üniversite öğrencilerinin sportif karakter durumlarının çeşitli değişkenler açısından değerlendirilmesi. Journal of Human Sciences, 16(4), 1197-1206. doi:10.14687/jhs.v16i4.5893

ways in compliance with social rules (Tamminen et al., 2012, Gee, 2010). There are also popular beliefs that sport has a positive effect on character (Kavussanu and Roberts, 2001; Sage, 1990; Sage and Kavussanu, 2007).

Sport is also considered as a tool in learning values such as cooperation with teammates, negotiation and solving ethical conflicts, justice, sportsmanship, team commitment, team work, responsibility, and submission for a greater good (Jang, 2013). The character of an athlete is formed through values such as being fair, compassionate, honest and social, and it corroborates the assumption that the high level of these values will help dealing with problems occurring in the sport field and regular and effective development of the beginning of the process of professionalization and long sportsperson life (Görgüt and Tuncel, 2017).

The study aimed to examine the sport personality traits (with the sub-dimensions of fair play, anti-socialness, integrity, ethical conduct) of university students who were actively involved in individual and team sports in terms age, gender, department and year of study variables and the difference between these variables.

\section{Method}

The participants of the study were 621 ( $n=220$ female, $n=401$ male) students who studied in the Faculty of Sport Sciences of Adnan Menderes University in Aydin province, Turkey in 20192020 academic year and who were actively involved in individual and team sport branches. In line with the aim of the study, a personal information form to determine the demographic characteristics was prepared, and Sport Character Scale which was developed by Chang-Yong Jang (2013) and adapted to Turkish by Görgüt and Tuncel (2017) was administered to the participants. The participants were given a personal information form prepared by the researcher in order to determine their gender, age, department, year of study and sport branch.

\section{Findings}

It was determined that the female participants' mean scores in fair play, anti-socialness, integrity, ethical conduct, sport character variables were higher than those of male participants (Table 2). Based on this data, it can be argued that females have much higher motivation for achieving sportive targets and that female participants' higher scores in fair play, anti-socialness, ethical conduct and sport character compared to males could be attributed to social and external factors affecting females.

In their study, İmamlı and Ünver (2018) found that female athletes' anti-socialness subdimension was higher in comparison to male athletes, whereas in the study carried out by Siyahtaş et al. (2018), male athletes were found to be more anti-social than female athletes. The difference in the anti-socialness status among athletes in terms of gender can be explained by several reasons. Among these reasons, the most prominent ones are the social environment in which females live, social gender discrimination and related unjust identification, positioning and practices (Bingöl, 2014). Consequently, it can be stated that the society and environmental factors have a significant impact on female athletes.

When Table 4 is examined, fair play, ethical conduct and sport character do not vary according to age $(p>0,05)$. However, it was determined that the anti-social behaviors of the individuals between the ages of 17 and 20 were higher than those of the individuals between the ages of 21 and 24 (Table 5). It can be claimed that the factors related to the general personality structures, characteristics and skills, and limited experiences of the students in the 17-20 age group may have resulted in higher anti-social behaviors.

Table 6 reveals that fair play, anti-socialness, integrity and sport character did not differ according to the participants' departments $(p>0,05)$. According to the data in Table 7 , no difference was identified in only ethical conduct sub-dimension in terms of year of study ( $p>0,05)$. A statistically significant difference was found between fair play, anti-socialness, integrity, sport character and the year of study $(\mathrm{p}<0.05)$. 
As can be seen in Table 8 , the mean score difference in the fair play variable of 1 st year students was found to be higher than that of the 2nd year students, and it was also determined that the mean score difference in anti-socialness variable of the 1 st year students were higher than those of the 2nd and 3rd year students. Again, it was found out that the mean score difference in the integrity variable of 1 st year students was higher than that of the 2 nd year students, and that the mean score difference in the integrity variable of 4 th year students was higher than that of the 1 st year students.

The mean score of the 1st year students in the sport character was found to be higher than that of the 2nd year students, the mean score of the 4th year students in terms of sport character was determined to be higher than that of the 1st year students.

According to the data in Table 9, no statistically significant difference was found between fair play, integrity, ethical conduct, sport character dimensions and type of sport $(p<0.05)$.

\section{Conclusion}

When the variables of fair play, anti-socialness, integrity and sport character were examined according to the type of sport, it was concluded that the mean score of the individuals who are involved in individual sport obtained from the variables of fair play, anti-socialness, integrity, ethical conduct and sport character was higher compared to the individuals involved in team sports. In this context, it can be argued that since an individual athlete is responsible for providing his/her own motivation during a competition or a game, the reason why he/she has a different sport character from those of team sport athletes can be accounted for by the fact that through his/her cognitive structure he/she can manage his/her self-confidence better and thus can control such behaviors better without being affected by any team mates.

* At the end of this study, other students from other faculties who do sports can be included in the study, and the effects of various factors in sport can be examined.

* Additional work and activities to develop sport character behaviors and some applications to increase success in sport can be organized.

* As a part the process of developing a good character, students cab ne provided with character development training. branches.

* In a future study, sport character behaviors can be examined in terms of other sport

* Students' individual characteristics should be better identified, their personality traits should be considered, and efforts should be made in order for these values to develop. 